\title{
Changes in telomerase activity due to alternative splicing of human telomerase reverse transcriptase in colorectal cancer
}

\author{
HEI CHEUL JEUNG ${ }^{1}$, SUN YOUNG RHA ${ }^{2}$, SANG JOON SHIN ${ }^{2}$, JOONG BAE AHN ${ }^{2}$, \\ KYU HYUN PARK ${ }^{2}$, TAE SOO KIM ${ }^{2}$, JIN JU KIM ${ }^{3}$, JAE KYUNG ROH ${ }^{2}$ and HYUN CHEOL CHUNG ${ }^{2}$ \\ ${ }^{1}$ Cancer Metastasis Research Center, Division of Medical Oncology, Cancer Center Gangnam Severance \\ Hospital, Yonsei University College of Medicine, Seoul 06273; ${ }^{2}$ Cancer Metastasis Research Center, Division \\ of Medical Oncology, Yonsei Cancer Center, Yonsei University College of Medicine, Seoul 03722; ${ }^{3}$ Department \\ of Laboratory Medicine, Inha University School of Medicine, Incheon 22332, Republic of Korea
}

Received September 9, 2015; Accepted February 27, 2017

DOI: $10.3892 / \mathrm{ol} .2017 .6438$

\begin{abstract}
Human telomerase reverse transcriptase (hTERT) expression level may not always correlate with telomerase activity. The present study analyzed hTERT splicing patterns with respect to hTERT and telomerase activity in colorectal cancer. Telomerase activity was determined by telomeric repeat amplification protocol assay, and spliced variants of hTERT were identified by reverse transcription-polymerase chain reaction in 40 colorectal cancer tissue samples. In the lower range of telomerase activity (0-100 units), the percentage of the $\beta$ variant decreased with the increment in telomerase activity, whereas in the higher range of telomerase activity (>100 units), total hTERT expression level revealed a trend toward increment. There was a positive correlation between the full-length variant level and $\beta$ variant level. Conversely, there was a negative correlation between the percentage of the full-length variant and $\beta$ variant. Tumor-node-metastasis stage was the strongest prognostic factor in multivariate analysis and the percentage of the full-length variant was an independent prognostic factor for survival. Telomerase activity was primarily altered with changes in alternative splicing of the full-length and $\beta$ variants of hTERT in colorectal cancer.
\end{abstract}

\section{Introduction}

Functional human telomerase reverse transcriptase (hTERT) mRNA is detected in lymphocytes (1) and in the normal brain, liver, prostate, heart and primary fibroblasts, irrespective of the degree of telomerase activity (2). The full-length Yonsei

Correspondence to: Professor Hyun Cheol Chung, Cancer Metastasis Research Center, Division of Medical Oncology, Yonsei Cancer Center, Yonsei University College of Medicine, 50-1 Yonsei Street, Seoul 03722, Republic of Korea

E-mail: unchung8@yuhs.ac

Key words: alternative splicing, telomerase activity, colorectal cancer, full-length, $\beta$ variant
hTERT variant is associated with high telomerase activity (3). However, the presence of a full-length hTERT variant is not sufficient to allow telomerase activity when an abundance of multiple hTERT spliced variants is concomitantly present (4).

A total of 6 alternative splicing sites (4 insertion and 2 deletion) have been identified within hTERT mRNA (5). Splice variants, depending on tissue type, continued to be synthesized even when the full-length variant was not (6). The presence of alternatively spliced variants in human preimplantation embryos may suggest a lack of telomerase activity, resulting in the appearance of chromosomes with shortened telomeres $(7,8)$. The exact functions of each alternatively spliced variant of hTERT remain unknown, although the positions of the spliced sites suggest that the majority of the variants do not code for functional reverse transcriptase. Depending on the cell line, this telomerase inhibition resulted either in cell death or a senescence-like state (9). The $\beta$ splice variant did not reconstitute active telomerase activity in a previous in vitro transcription and translation study (10). The alteration of hTERT full-length variant expression levels has previously been reported to demonstrate various gene expression profiles and genomic copy number changes in cancer cell lines (11).

In telomerase-positive cell lines, there is a highly uniform pattern of splicing. In total, $5 \%$ of hTERT mRNA is in full-length form, $80-90 \%$ in $\beta$-spliced form, $5-15 \%$ in $\alpha / \beta$-spliced form and $<1 \%$ in $\alpha$-spliced form (12). However, in contrast, considerable variation in the total number and quantitative distribution of spliced variants has been observed in various cancer tissues and in normal tissues. In renal cell carcinoma, the $\beta$ variant was the major type and the $\alpha$ variant was not detected (13). In breast cancer, the $\alpha$ variant was always coexpressed with the full-length and/or $\beta$ variant, otherwise, the full-length and $\beta$ variant were observed either in combination with other transcripts or expressed as the only hTERT transcript (14). Melanoma expressed full-length transcripts with various combinations of $\alpha, \beta$ and $\alpha / \beta$ variants, although a prevalence of the $\beta$ variant was observed (4).

The presence of a full-length variant was correlated with telomerase activity in the endometrium and myometrium (15). Two potential mechanisms underlying the reduction of telomerase activity with differentiation have previously been 
suggested: One is the post-translational alterations in hTERT with stable total transcription and splicing patterns, and the other is the minimal change in total transcription with a dramatic decrease of the full-length variant, predominantly remaining in $\beta$-spliced form (13).

The aim of the present study was to analyze the hTERT splicing pattern in association with telomerase activity in patients with colorectal cancer.

\section{Materials and methods}

Tissue sampling and RNA isolation. A total of 40 patients who underwent surgery between May 2002 and May 2003 at Yonsei Cancer Center, Severance Hospital, Yonsei University Health System (Seoul, Korea) were enrolled in the present study. Clinical characteristics of the patients are listed in Table I. Paired tumor tissues and normal tissues from 30 patients and tumor tissues alone from 10 patients were studied. Tumor tissues ( $\geq 70 \%$ carcinoma cellularity) were frozen immediately following surgery. In paired samples, normal tissues $10 \mathrm{~cm}$ from the lateral margin of the primary tumor were obtained. Total RNA was isolated from cells and tissues using TRIzol reagent (Invitrogen; Thermo Fisher Scientific, Inc., Waltham, MA, USA), according to the manufacturer's protocol. Approval for the present study was obtained from the institutional review board of the Severance Hospital (Seoul, Korea; approval no. IRB-4-2004-0083). Written, informed consent was obtained from all patients for the use of the samples in the present study.

Telomeric repeat amplification protocol (TRAP) assay. Each tissue sample was washed in ice-cold wash buffer $[10 \mathrm{mM}$ Hepes-KOH (pH 7.5), $1.5 \mathrm{mM} \mathrm{MgCl}_{2}, 10 \mathrm{mM} \mathrm{KCl}, 1 \mathrm{mM}$ dithiothreitol] and then homogenized with $100 \mu \mathrm{l}$ ice-cold lysis buffer [10 mM Tris- $\mathrm{HCl}$ (pH 7.5), $1 \mathrm{mM} \mathrm{MgCl}_{2}, 1 \mathrm{mM}$ egtazic acid (EGTA), $0.1 \mathrm{mM}$ phenylmethylsulfonyl fluoride, $5 \mathrm{mM} \beta$-mercaptoethanol, $0.5 \%$ CHAPS, $10 \%$ glycerol]. The TRAP assay was performed as follows: A total of $20 \mu \mathrm{l}$ of each extract was assayed in a $50 \mu 1$ reaction mixture supplemented with $20 \mathrm{mM}$ Tris- $\mathrm{HCl}$ ( $\mathrm{pH} 8.3$ ), $1.5 \mathrm{mM} \mathrm{MgCl}$, $63 \mathrm{mM} \mathrm{KCl}$, $0.005 \%$ Tween-20, 1 mM EGTA, $50 \mu \mathrm{M}$ deoxynucleotide triphosphates, $0.5 \mu \mathrm{l}\left(\alpha{ }^{3} \mathrm{P}\right)$ deoxycytidine triphosphate (dCTP; 3,000 Ci/mmol; GE Healthcare Life Sciences, Chalfont, UK), $0.1 \mu \mathrm{g}$ template-switching oligonucleotide (5'-AATCCGTCG AGCAGAGTT-3'), $1 \mu \mathrm{g}$ T4 gene 32 protein, bovine serum albumin (0.1 mg/ml; Sigma-Aldrich; Merck KGaA, Darmstadt, Germany) and 2 U Taq DNA polymerase (Applied Biosystems; Thermo Fisher Scientific, Inc.) in an assay tube supplemented with $0.1 \mu \mathrm{g} \mathrm{CX}$ primer (5'-CCCTTACCCTTACCCTTACCC TAA-3'). The reaction mixture was amplified for 30 cycles at $94^{\circ} \mathrm{C}$ for $30 \mathrm{sec}, 50^{\circ} \mathrm{C}$ for $30 \mathrm{sec}, 72^{\circ} \mathrm{C}$ for $90 \mathrm{sec}$, and then for $10 \mathrm{~min}$ at $72^{\circ} \mathrm{C}$. Analysis of $10 \mu \mathrm{l}$ of each polymerase chain reaction $(\mathrm{PCR})$ product was performed on $12 \%$ non-denaturing acrylamide gels. The present study also determined the optical density (OD) of the bands in the film by computer-assisted densitometry (Vilber Lourmat Vision-Capt software version 1; Vilber Lourmat, Marne-la-Vallée, France). The OD of the band with the greatest density in $6 \mu \mathrm{g}$ protein from the human normal kidney immortalized cell line which displays telomerase activity (HEK-293 cell line) was arbitrarily defined as
$100 \mathrm{U}$ (16). In order to compare the ODs of telomerase activity from each tissue with the same baseline, TRAP assays were performed using the same amount of tissue extracts $(6 \mu \mathrm{g})$ in all 40 patients. The bands from each tissue were compared with the control (HEK-293 cell line) and expressed in arbitrary units $(11,17,18)$.

Alternative splicing of hTERT. Total RNA was collected from samples using TRIzol-Reagent (Thermo Fisher Scientific, Inc.). First-strand cDNA synthesis was performed according to the manufacturer's protocol. Total RNA $(1 \mu \mathrm{g})$, oligo(dT) primer, $10 \mathrm{mM}$ dNTPs and M-MuLV reverse transcriptase (Fermentas; Thermo Fisher Scientific, Inc.) was used to synthesize cDNA for each sample. In order to evaluate hTERT mRNA splicing, the present study performed reverse transcription-PCR using primer sets for the reverse transcriptase domain of the hTERT transcript (19). The cDNA samples were amplified in a $5 \mu \mathrm{l}$ reaction mixture supplemented with $0.25 \mathrm{uCi}\left(\alpha-{ }^{32} \mathrm{P}\right) \mathrm{dCTP}$ (GE Healthcare Life Sciences) and $0.2 \mu \mathrm{M}$ of each primer. The first hTERT cDNA amplification used TERT-1784S, 5'-CGGAAGAGTGTCTGGAGCAA-3' and TERT-1928A, 5'-GGATGAAGCGGAGTCTGGA-3' oligonucleotides with an initial heating at $94^{\circ} \mathrm{C}$ for $90 \mathrm{sec}$, followed by 33 cycles of $95^{\circ} \mathrm{C}$ for $20 \mathrm{sec}, 68^{\circ} \mathrm{C}$ for $40 \mathrm{sec}$ and $72^{\circ} \mathrm{C}$ for $30 \mathrm{sec}$. Primers 774 (forward; 5'-GGGAATTCAAAACTGGAACGGTGA AGG-3') and 775 (reverse; 5'-GGAAGCTTATCAAAGTCC TCGGCCACA- $3^{\prime}$ ) were added at $72^{\circ} \mathrm{C}$ during cycle 13 as a $\beta$-actin internal control. The second hTERT cDNA amplification used TERT-2164S sense, 5'-GCCTGAGCTGTACTT TGTCAA-3' and TERT-2620A anti-sense, 5'-CGCAAACAG CTTGTTCTCCATGTC-3' oligonucleotides (6) with an initial heating at $94^{\circ} \mathrm{C}$ for $90 \mathrm{sec}$, followed by 35 cycles of $95^{\circ} \mathrm{C}$ for $25 \mathrm{sec}, 68^{\circ} \mathrm{C}$ for $50 \mathrm{sec}$ and $72^{\circ} \mathrm{C}$ for $50 \mathrm{sec}$. Primers 774 and 775 were added at $72^{\circ} \mathrm{C}$ during cycle 15 as a $\beta$-actin internal control. Bands from each tissue were compared with the control and expressed in arbitrary units. The HL-60 cell line (American Tissue Type Culture Collection, Manassas, VA, USA) was used as a positive control for the expression level of alternatively spliced variants.

Statistical analysis. Clinical data were retrieved from the medical records of Severance Hospital (Seoul, Korea). The $\chi^{2}$ test or Mann-Whitney U tests were used for categorical variables and the Student's t-test was used to compare continuous variables. Progression-free survival (PFS) was defined as the time interval between the date of surgery and disease progression or mortality from any cause. Overall survival (OS) was evaluated from the date of surgery to mortality or last contact (censored observation). Survival curves were estimated using the Kaplan-Meier method and differences in survival curves among groups were compared using the log-rank test. Univariate associations between prognostic factors and OS and between prognostic factors and PFS were assessed using the log-rank test. In order to adjust for confounding variables, Cox proportional hazards models were used to estimate the simultaneous effects of prognostic factors on survival. All tests were two-sided and $\mathrm{P}<0.05$ was considered to indicate a statistically significant difference. All analyses were performed using SPSS for Windows (version 13.0; SPSS, Inc., Chicago, IL, USA). 
Table I. Patient characteristics.

\begin{tabular}{|c|c|}
\hline Clinical factors & Patient number $(\%$ \\
\hline Age (median, range; years) & $66(44-81)$ \\
\hline \multicolumn{2}{|l|}{ Sex } \\
\hline Male & $25(62.5)$ \\
\hline Female & $15(37.5)$ \\
\hline \multicolumn{2}{|c|}{ Eastern Cooperative Oncology Group ${ }^{a}$} \\
\hline $0-1$ & $40(100)$ \\
\hline \multicolumn{2}{|l|}{ Primary site } \\
\hline Colon cancer & $23(57.5)$ \\
\hline Rectal cancer & $17(42.5)$ \\
\hline \multicolumn{2}{|l|}{ Stage $(\text { Duke })^{\mathrm{b}}$} \\
\hline A & $1(2.5)$ \\
\hline $\mathrm{B}$ & $21(52.5)$ \\
\hline $\mathrm{C}$ & $13(32.5)$ \\
\hline $\mathrm{D}$ & $5(12.5)$ \\
\hline \multicolumn{2}{|l|}{ Stage (TNM) } \\
\hline $\mathrm{I}$ & $3(7.5)$ \\
\hline II & $19(47.5)$ \\
\hline III & $13(32.5)$ \\
\hline IV & $5(12.5)$ \\
\hline \multicolumn{2}{|l|}{ Operation type } \\
\hline Low anterior resection & $26(65.0)$ \\
\hline Right hemicolectomy & $9(22.5)$ \\
\hline Left hemicolectomy & $5(12.5)$ \\
\hline \multicolumn{2}{|l|}{ Relapse } \\
\hline No recurrence & $28(70.0)$ \\
\hline Recurrence & $12(30.0)$ \\
\hline \multicolumn{2}{|l|}{ Survival rate } \\
\hline Survived & $31(77.5)$ \\
\hline Succumbed & $9(22.5)$ \\
\hline $\begin{array}{l}\text { Follow-up duration } \\
\text { (median, range; months) }\end{array}$ & $69.5(7.4-76.3)$ \\
\hline
\end{tabular}

a Oken et al (31). ${ }^{\mathrm{b}}$ Astler and Coller (32). TNM, tumor-node-metastasis .

\section{Results}

Patient characteristics. Of the 40 patients enrolled in the present study, the median follow-up duration was 69.5 months (range, 7.4-76.3 months). During the follow-up period, 12 $(30.0 \%)$ of patients relapsed and $9(22.5 \%)$ succumbed to colorectal cancer. The five-year DFS and OS rates were $76.3 \%$ and $81.6 \%$, respectively. Other clinical characteristics are summarized in Table I.

Expression levels of telomerase activity and hTERT. Of the 40 tumor tissues, 32 (80\%) expressed telomerase activity and $32(80 \%)$ expressed hTERT. Of the 32 patients with telomerase activity, $26(81 \%)$ expressed hTERT. In the 8 patients without telomerase activity, 6 (75\%) expressed hTERT. A total of 2 patients did not express telomerase activity or hTERT (Table II).
Table II. Comparison of telomerase activity and hTERT expression levels in colon cancer tissues $(n=40)$.

\begin{tabular}{llc}
\hline Telomerase activity & hTERT expression & Patient no. (\%) \\
\hline Positive & Expressed & $26(65 \%)$ \\
Positive & Non-expressed & $6(15 \%)$ \\
Negative & Expressed & $6(15 \%)$ \\
Negative & Non-expressed & $2(5 \%)$ \\
\hline
\end{tabular}

hTERT, human telomerase reverse transcriptase.

Table III. Comparison of telomerase activity and percent fraction of hTERT variants.

Telomerase

activity range and Full hTERT

mean $\pm \mathrm{SD}(\mathrm{U}) \quad(\%) \quad \alpha(\%) \quad \beta(\%) \quad \alpha \beta(\%) \quad(\mathrm{U})$

\begin{tabular}{llllrc}
\hline $0-50(8 \pm 11)$ & $22 \pm 13$ & $2 \pm 2$ & $71 \pm 18^{\mathrm{a}}$ & $5 \pm 4$ & $63 \pm 47^{\mathrm{b}}$ \\
$51-100(75 \pm 14)$ & $34 \pm 21$ & $4 \pm 4$ & $53 \pm 23^{\mathrm{a}}$ & $9 \pm 7$ & $51 \pm 79$ \\
$101-200(122 \pm 21)$ & $31 \pm 6$ & $3 \pm 3$ & $58 \pm 7$ & $10 \pm 8$ & $58 \pm 36$ \\
$>200(323 \pm 76)$ & $25 \pm 15$ & $4 \pm 3$ & $65 \pm 19$ & $6 \pm 5$ & $101 \pm 55^{\mathrm{b}}$
\end{tabular}

hTERT, human telomerase reverse transcriptase; SD, standard deviation; $\alpha, \alpha$ variant; $\beta, \beta$ variant; $\alpha \beta, \alpha / \beta$ variant. ${ }^{a} \beta(\%)$ in telomerase activity 0-50 group vs. $51-100$ group, $\mathrm{P}=0.048$; ${ }^{\mathrm{h}} \mathrm{hTERT}(\mathrm{U})$ in telomerase activity $0-50$ group vs. $>200$ group, $\mathrm{P}=0.06$.

In the lower range of telomerase activity (0-100 U), the percentage of $\beta$ variant decreased with the increment in telomerase activity $(\mathrm{P}=0.048)$, whereas hTERT did not significantly differ. In the higher range of telomerase activity $(\geq 100 \mathrm{U})$, total hTERT level revealed a trend toward increment $(\mathrm{P}=0.06)$ without any difference in the percentage of each spliced type (Table III; Fig. 1). These results suggested that a change of $\beta$ variant percentage was the main mechanism during the early phase and that hTERT increment was the main mechanism of the late phase of telomerase activity increment in colorectal cancer.

Expression levels of hTERT splicing variants. Among the 30 paired normal tissues, 1 patient $(3.3 \%)$ expressed a low level of telomerase activity (36 U) and 1 patient expressed hTERT (20 U). A total of 4 patients (13.3\%) expressed alternatively spliced variants [1 full-length (87 U), $\alpha$ (25 U), $\beta$ $(120 \mathrm{U})$ variants; 1 full-length $(1 \mathrm{U})$ and $\beta(1 \mathrm{U})$ variants; 2 $\beta$ variant alone $(12,21 \mathrm{U})]$. In cancer tissues with telomerase activity, $17(53 \%)$ of patients expressed all 4 types of variants (full length, $\alpha, \beta$ and $\alpha / \beta$ ). A total of 7 patients $(22 \%$ ) expressed full-length, $\beta$ and $\alpha / \beta$ variants. A total of $3(9 \%)$ patients expressed full length and $\beta$ variants (Fig. 2). A total of 3 patients expressed none of the hTERT types, even with telomerase activity expression. Of the 8 patients without telomerase activity, 2 did not express any hTERT splicing type. A total of 2 patients expressed all 4 types (Table IV). 

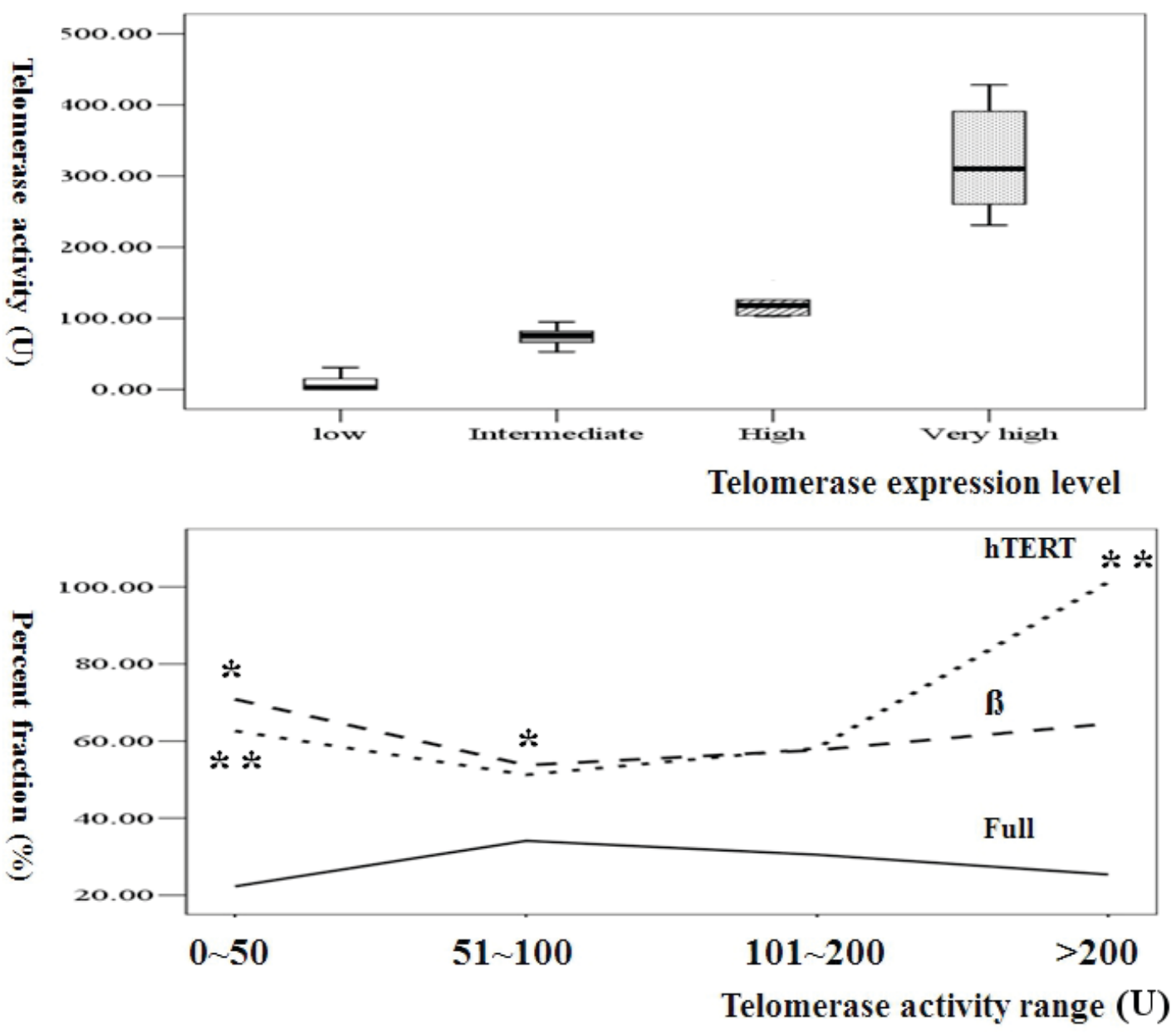

Figure 1. Changes in hTERT expression levels, percent fractions of full-length and $\beta$ variants based on the alterations in telomerase activity. (A) Changes in telomerase activity. (B) Changes in hTERT expression level, including full-length and $\beta$ variants. hTERT, human telomerase reverse transcriptase. ${ }^{*} \mathrm{P}=0.048$, $\beta(\%)$ in telomerase activity 0-50 group vs. 51-100 group and ${ }^{* *} \mathrm{P}=0.06$, hTERT (U) in telomerase activity 0-50 group vs. $>200$ group.

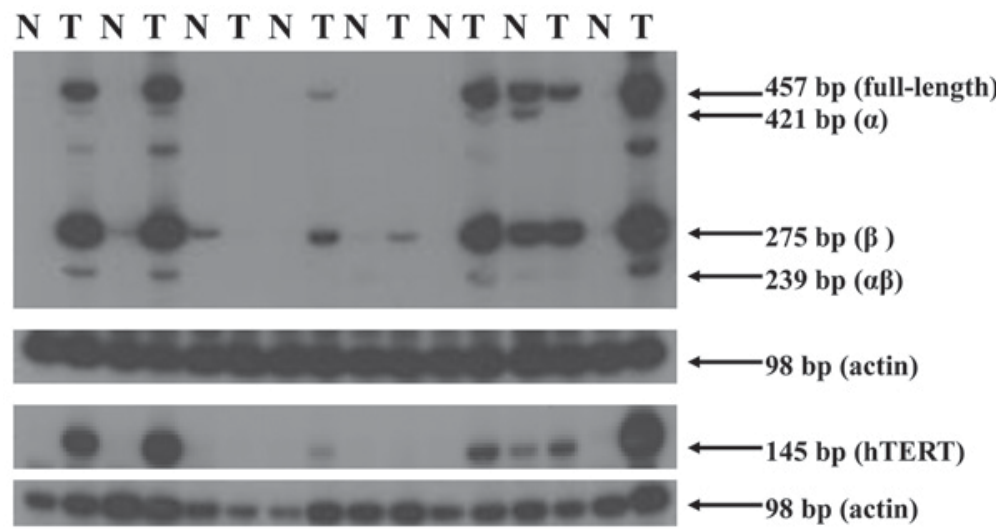

Figure 2. A total of 8 paired normal and cancer tissues that expressed full-length, $\alpha, \beta$ or $\alpha \beta$ variants and hTERT compared with actin expression levels. hTERT, human telomerase reverse transcriptase; bp, base pair; $\mathrm{N}$, normal tissue; $\mathrm{T}$, tumor tissue.

Comparison of telomerase activity based on hTERT splicing variant expression level. There was no difference in telomerase activity in each group when telomerase activity based on the expression levels of splicing types was compared; however, hTERT expression levels were lower in 2 groups (full-length, $\beta$ and $\alpha / \beta ; P=0.09 ;$ and full-length, $\beta ; \mathrm{P}<0.0008$ ) compared with the group with all 4 variant types expressed (Table IV).
There was no correlation between telomerase activity and expression level of each variant. However, among the variants, there was a positive correlation between full-length variant level and $\beta$ variant level ( $r=0.88, P<0.001$; Fig. 3). Conversely, there was a negative correlation in the percentage between the full-length variant and $\beta$ variant $(r=-0.939, P<0.001$; Fig. 3). Expression fractions of full-length and $\beta$ variants were 
Table IV. Expression level of hTERT splicing variants based on telomerase activity.

\begin{tabular}{lccc}
\hline Group & Patient number & Telomerase activity (U) & hTERT expression level (U) \\
\hline Telomerase activity $(+)(\mathrm{n}=32)$ & 17 & $146 \pm 130$ & $92 \pm 62^{\mathrm{a}, \mathrm{b}}$ \\
Full $/ \alpha / \beta / \alpha \beta$ & 7 & $111 \pm 133$ & $55 \pm 45^{\mathrm{a}}$ \\
Full $/ \beta / \alpha \beta$ & 3 & $144 \pm 149$ & $13 \pm 14^{\mathrm{b}}$ \\
Full $/ \beta$ & 1 & 95 & 1 \\
Full/ $\alpha / \beta$ & 1 & 21 & 0 \\
$\beta$ & 3 & $210 \pm 336$ & 0 \\
None & & & \\
Telomerase activity (-) $(\mathrm{n}=8)$ & & & \\
Full $/ \alpha / \beta / \alpha \beta$ & 2 & & \\
Full $/ \alpha / \alpha \beta$ & 2 & & \\
$\beta / \alpha \beta$ & 1 & & \\
$\beta$ & 1 & & \\
None & 2 & & \\
\end{tabular}

${ }^{a}$ hTERT expression level in Full $/ \alpha / \beta / \alpha \beta$ group vs. Full $/ \beta / \alpha \beta$ group, $\mathrm{P}=0.09 ;{ }^{b}$ hTERT expression level in Full/ $\alpha / \beta / \alpha \beta$ group vs. Full/ $\beta$ group, $\mathrm{P}<0.0008$. hTERT, human telomerase reverse transcriptase; $\alpha, \alpha$ variant; $\beta, \beta$ variant; $\alpha \beta, \alpha / \beta$ variant.

A

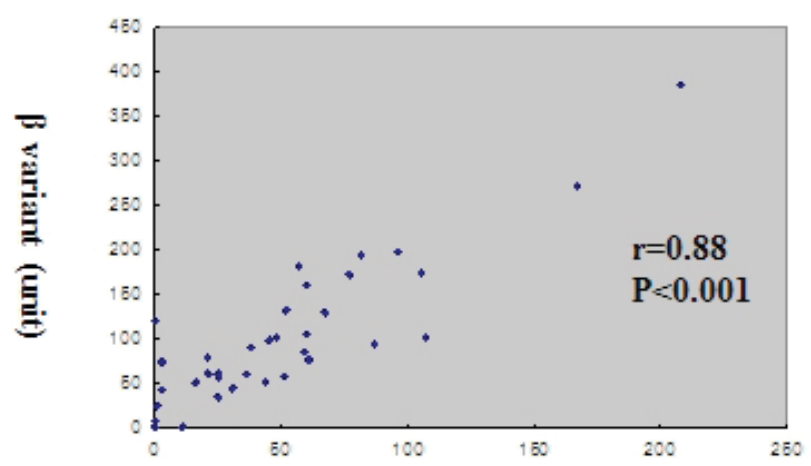

Full-length variant (unit)

C

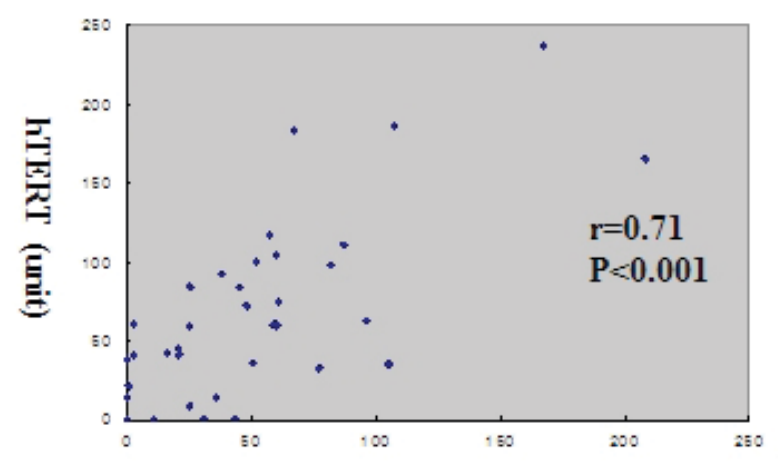

Full-length variant (unit)
B

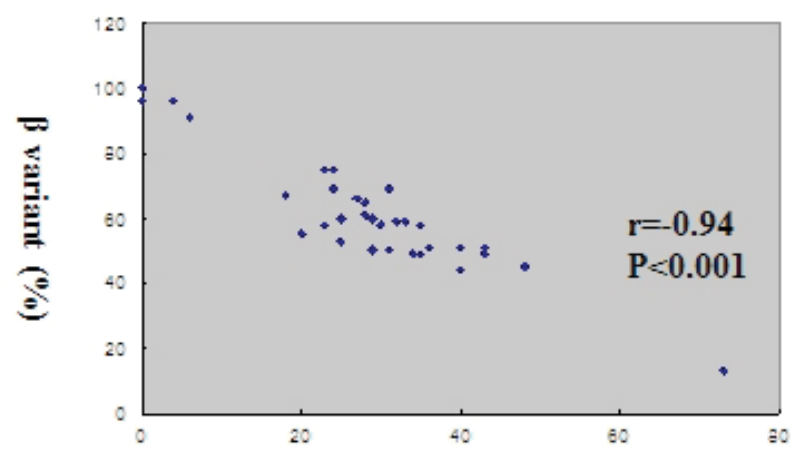

Full-length variant $(\%)$

D

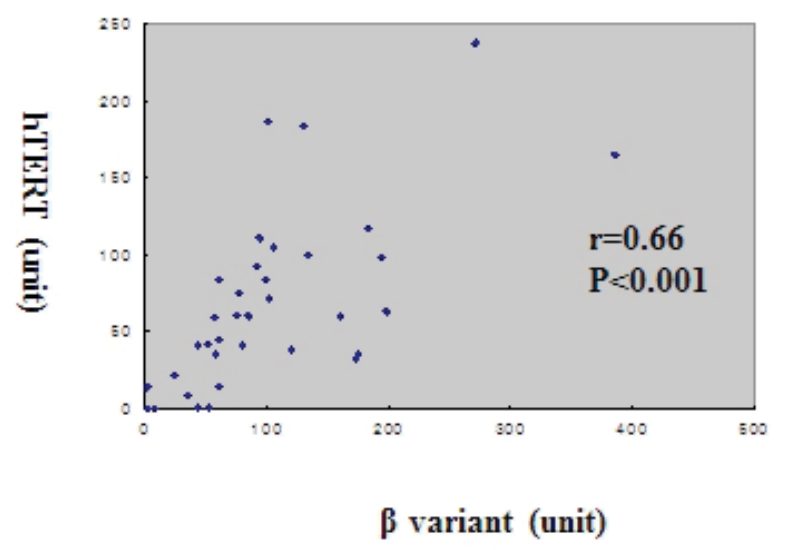

Figure 3. Correlations of hTERT, full-length and $\beta$ variant expression levels. (A) Positive correlation of expression levels of full-length and $\beta$ variants. (B) Negative correlation of percent fractions between full-length and $\beta$ variants. (C) Positive correlation of expression levels between full-length variants and hTERT. (D) Positive correlation of expression levels between $\beta$ variant and hTERT. hTERT, human telomerase reverse transcriptase. 
Table V. Multivariate analysis of hazard ratio for overall survival in patients with colorectal cancer.

\begin{tabular}{lcrl}
\hline Variable & P-value & Hazard ratio & \multicolumn{1}{c}{$95 \%$ CI } \\
\hline Age & 0.231 & 0.757 & $0.480-1.194$ \\
Sex & 0.525 & 5.471 & $0.029-1033.948$ \\
Telomerase activity & 0.596 & 0.994 & $0.973-1.016$ \\
$\alpha / \beta$ ratio (\%) & 0.215 & 1.209 & $0.895-1.633$ \\
TNM stage & $0.027^{\mathrm{a}}$ & 24.125 & $1.429-407.290$ \\
Full length (\%) & $0.037^{\mathrm{b}}$ & 1.294 & $1.016-1.647$ \\
hTERT & 0.903 & 0.998 & $0.968-1.029$ \\
\hline
\end{tabular}

CI, confidence interval; TNM, tumor-node-metastasis; hTERT, human telomerase reverse transcriptase. ${ }^{\mathrm{a}} \mathrm{P}<0.05$, TNM stage I=II vs . III+IV, ${ }^{b} \mathrm{P}<0.05$, full Length $(\%) \leq 50 \%$ vs. $>50 \%$.

positively correlated with hTERT expression level $(\mathrm{r}=0.71$, $\mathrm{P}<0.001$ and $\mathrm{r}=0.66, \mathrm{P}<0.001$, respectively; Fig. 3). Even if total levels of full length and $\beta$ variants increased with the increment of hTERT expression level, the main factor for the hTERT increment was full-length variant increment, which resulted in a negative correlation between hTERT level and percent fraction of $\beta$ variant. This finding suggested that full-length variant was the main subtype of splicing during the increment of hTERT in colorectal cancer.

Comparison of clinical parameters with splicing type pattern. The present study compared the hazard ratio for survival with clinical factors [age, sex, tumor-node-metastasis (TNM) stage (20)] and molecular markers (telomerase activity, percent fraction of alternative splicing types, hTERT). TNM stage was demonstrated to be the strongest prognostic factor by multivariate analysis, and percent fraction of the full-length variant was an independent prognostic factor for survival (Table V).

\section{Discussion}

The discrepancy between telomerase activity and the hTERT mRNA expression levels may be due to the difficulty of quantification of either telomerase activity or hTERT expression level, constituents of intratumoral lymphocytes or leukocytes or the presence of heterogeneity in tumor tissues. Finally, post-transcriptional modification of telomerase activity by alternative splicing may result in truncated and potentially dysfunctional protein products.

The association of telomerase activity with the presence of the full-length variant was significant (3). However, the presence of a full-length hTERT variant was not sufficient to allow telomerase activity when an abundance of hTERT-spliced variants were concomitantly present (11). In melanoma, the $\beta$-spliced form was a negative regulator of telomerase activity (21). In the present study, 4 (12.5\%) of the 32 patients with telomerase activity lacked the full length variant, and of the 8 patients without detectable telomerase activity, $4(50 \%)$ lacked the full-length variant and $4(50 \%)$ lacked the $\beta$ variant. These cases suggested the presence of an additional regulatory mechanism, for example post-translational modification by phosphorylation or truncation outside the reverse transcriptase motif of hTERT.

Various splice variants, depending on the tissue type, continue to be synthesized when the full-length variant is not (22). Two potential mechanisms underlying the decrement of telomerase activity with differentiation have been previously suggested $(22,23)$. These are posttranslational alterations in hTERT with stable total transcription and splicing patterns, and minimal change in total transcription with a decrement of the full-length variant predominantly remaining in $\beta$-spliced form (12). In a previous in vitro transcription and translation study, the $\beta$-splice variant was revealed to not reconstitute an active telomerase enzyme (3). It is possible that protein products of $\alpha$ - or $\beta$-spliced transcripts are negative inhibitors of the formation of active telomerase enzymes. In the patients investigated in the present study, when there was a low increment of telomerase activity, the initial decrement of the $\beta$ variant fraction was demonstrated without any specific increment of hTERT. However, in patients with high telomerase activity, total hTERT level was increased with stable maintenance of each variant fraction. Various regulatory mechanisms may be involved based on different levels of telomerase activity in colorectal cancer, including shifting of $\beta$ variant fractions and total increments of hTERT.

In general, the band density of the full-length variant was equal to or higher than that of alternatively spliced variants. Transcriptional activation of hTERT is not necessarily the rate-limiting step in the generation of functional telomerase. The present study observed decreased hTERT levels without any changes in telomerase activity in patients without the $\alpha$-splice variant compared with patients with all 4 variants. Although the $\alpha$ variant did not completely abolish telomerase activity, the resultant reduction in activity was sufficient to reverse the immortal phenotype (9). Clones expressing the $\alpha$ variant underwent apoptosis and clones expressing the $\beta$ variant or $\alpha / \beta$ variant revealed no sign of apoptosis and continued to proliferate (12).

The hTERT level was positively correlated with expression levels of the full-length variant and the $\beta$ variant in the patients included in the present study. With the increment of total hTERT, the full-length variant and $\beta$ variant expression levels increased with positive correlations. However, when the percent fraction of each variant and hTERT expression level were compared, the full-length variant was positively correlated and the $\beta$ variant was negatively correlated. Therefore, in patients with hTERT increment, the increment rate of the full-length variant was higher than the increment rate of the $\beta$ variant. As a result, even if the total amount of the $\beta$ variant was increased, the total fraction was relatively low compared with the fraction of the full-length variant. These relative changes in the fraction and total amount of each spliced variant may be the regulatory mechanism underlying hTERT, and thus telomerase activity in colorectal cancer. Of the transcriptional regulators of hTERT, nuclear factor of activated T cells (24), SET and MYND domain-containing protein 3, a histone methyltransferase (25), Mutant-S homolog 2, heterogeneous nuclear ribonuclear protein (hnRNP) D, hnRNP K and grainyhead-like 2 (26) have been observed in cancer cells, and mad1 was identified in myelodysplastic syndrome (27), which 
may be targets for anti-telomerase or anti-hTERT treatment in cancer.

The cyclopentenone prostaglandin 15-deoxy-delta 12,14-prostaglandin J2 demonstrated anti-neoplastic activity by decreasing hTERT expression level and suppressing c-Myc mRNA expression levels (28). A low dose of chelidonine reduced telomerase activity via downregulation of hTERT expression, suggesting that hTERT may be a potential target molecule in cancer (29). In the patients enrolled in the present study, there was no significant difference in clinical outcome between patients with telomerase-positive and negative colorectal cancer. However, the percent fraction of the full-length variant was a prognostic factor, as was American Joint Committee on Cancer (TNM) stage. When developing an anti-telomerase drug treatment, $80 \%$ of patients with colorectal cancer may be a potential target population, using hTERT variant as a patient selection biomarker (30).

In conclusion, telomerase activity changes and alternative splicing of full-length and $\beta$ variants of hTERT in colorectal cancer were demonstrated. Clinical trials with an anti-telomerase compound using alternative splicing variants as patient selection biomarkers are warranted for the validation of the clinical significance of hTERT variants in colorectal cancer.

\section{Acknowledgements}

The present study was supported by the Korea Health $21 \mathrm{R} \& \mathrm{D}$ Project, Ministry of Health \& Welfare, Republic of Korea (grant no. 0405-BC01-0604-0002).

\section{References}

1. Liu K, Schoonmaker MM, Levine BL, June CH, Hodes RJ and Weng NP: Constitutive and regulated expression of telomerase reverse transcriptase (hTERT) in human lymphocytes. Proc Natl Acad Sci USA 96: 5147-5152, 1999.

2. Ramakrishnan S, Eppenberger U, Mueller H, Shinkai Y and Narayanan R: Expression profile of the putative catalytic subunit of the telomerase gene. Cancer Res 58: 622-625, 1998.

3. Krams M, Claviez A, Heidorn K, Krupp G, Parwaresch R, Harms D and Rudolph P: Regulation of telomerase activity by alternate splicing of human telomerase reverse transcriptase mRNA in a subset of neuroblastomas. Am J Pathol 159: 1925-1932, 2001.

4. Villa R, Porta CD, Folini M, Daidone MG and Zaffaroni N: Possible regulation of telomerase activity by transcription and alternatively splicing of telomerase reverse transcriptase in human melanoma. J Invest Dermatol 116: 867-873, 2001.

5. Killian A, Bowtell DD, Abud HE, Hime GR, Venter DJ, Keese PK, Duncan EL, Reddel RR and Jefferson RA: Isolation of a candidate human telomerase catalytic subunit gene, which reveals complex splicing patterns in different cell types. Hum Mo Genet 6: 2011-2019, 1997.

6. Ulaner GA, Hu JF, Vu TH, Giudice LC and Hoffman AR: Telomerase activity in human development is regulated by human telomerase reverse transcriptase (hTERT) transcription and by alternate splicing of hTERT transcripts Cancer Res 58 4168-4172, 1998.

7. Ulaner GA, Hu JF, Vu TH, Giudice LC and Hoffman AR: Tissue-specific alternate splicing of human telomerase reverse transcriptase (hTERT) influences telomere lengths during human development. Int J Cancer 91: 644-649, 2001.

8. Brenner CA, Wolny YM, Adler RR and Cohen J: Alternative splicing of the telomerase catalytic subunit in human oocytes and embryos. Mol Human Repro 5: 845-850, 1999.

9. Colgin LM, Wilkinso C, Englezou A, Kilian A, Robinson MO and Reddel RR: The hTERTalpha splice variant is a dominant negative inhibitor of telomerase activity. Neoplasia 2: 426-432, 2000 .
10. Weinrich SL, Pruzan R, Ma L, Ouellette M, Tesmer VM, Holt SE, Bodnar AG, Lichtsteiner S, Kim NW, Trager JB, et al: Reconstitution of human telomerase with the template RNA component hTR and the catalytic protein subunit hTRT. Nat Genet 17: 498-502, 1997.

11. Rha SY, Jeung HC, Yang WI, Kim JJ, Oh TJ, An SW and Chung HC: Alteration of hTERT full-length variant expression level showed different gene expression profiles and genomic copy number changes in breast cancer. Oncol Rep 15: 749-755, 2006.

12. Yi X, Shay JW and Wright WE: Quantitation of telomerase components and hTERT mRNA splicing patterns in immortal human cells. Nucleic Acid Res 29: 4818-4825, 2001.

13. Hara T, Noma T, Yamashiro Y, Naito $K$ and Nakazawa $A$ : Quantitative analysis of telomerae activity and telomerase reverse transcriptase expression in renal cell carcinoma. Urol Res 29: 1-6, 2001.

14. Zaffaroni N, Della Porta C, Villa R, Botti C, Buglioni S, Mottolese M and Grazia Daidone M: Transcription and alternative splicing of telomerase reverse transcriptase in benign and malignant breast tumours and in adjacent mammary glandular tissues: Implications for telomerase activity. J Pathol 198: 37-46, 2002.

15. Yokoyama Y, Wan X, Takahashi Y, Shinohara A and Tamaya T: Alternatively spliced variant deleting exon 7 and 8 of the human telomerase reverse transcriptase gene is dominantly expressed in the uterus. Mol Hum Repro 7: 853-857, 2001.

16. Wright WE, Shay JW and Piatyszek MA: Modifications of a telomeric repeat amplification protocol (TRAP) result in increased reliability, linearity and sensitivity. Nucleic Acid Res 23: 3794-3795, 1995.

17. Park KH, Rha SY, Kim CH, Kim TS, Yoo NC, Kim JH, Roh JK, Noh SH, Min JS, Lee KS, et al: Telomerase activity and telomere lengths in various cell lines: Changes of telomerase activity can be another method for chemosensitivity evaluation. Int J Oncol 13: 489-495, 1998.

18. Rha SY, Park KH, Kim TS, Yoo NC, Yang WI, Roh JK, Min JS, Lee KS, Kim BS, Choi JH, et al: Changes of telomerase and telomere lengths in paired normal and cancer tissues of breast. Int J Oncol 15: 839-845, 1999.

19. Yeo M, Rha SY, Jeung HC, Hu SX, Yang SH, Kim YS, An SW and Chung HC: Attenuation of telomerase activity by hammerhead ribozyme targeting human telomerase RNA induces growth retardation and apoptosis in human breast tumor cells. Int J Cancer 114: 484-489, 2005.

20. Sobin LH, Gospodarowicz MK and Wittekind C: TNM classification of malignant tumors 7th edition. New York: Wiley 200921.

21. Lincz LF, Mudge LM, Scorgie FE, Sakoff JA, Hamilton CS and Seldon M: Quantitation of hTERT splice variants in melanoma by SYBR green real-time polymerase chain reaction indicates a negative regulatory role for the beta deletion variant. Neoplasia 10: 1131-1137, 2008.

22. Jalink M, Ge Z, Liu C, Björkholm M, Gruber A and Xu D: Human normal $\mathrm{T}$ lymphocutes and lymphoid cell lines do express alternative splicing variants of human telomerase reverse transcriptase (hTERT) mRNA. Biochem Biophys Res Commun 353: 999-1003, 2007.

23. Shervington A and Patel A: Differential hTERT mRNA processing between young and older glioma patients. FEBS Lett 582: $1707-1710,2008$.

24. Chebel A, Rouault JP, Urbanowicz I, Baseggio L, Chien WW, Salles G and Ffrench W: Transcriptional activation of HTERT, the human telomerase reverse transcriptase, by nuclear factor of activated T cells. J Biol Chem 284: 35725-35734, 2009.

25. Liu C, Fang X, Ge Z, Jalink M, Kyo S, Björkholm M, Gruber A, Sjöberg J and Xu D: The telomerase reverse transcriptase (hTERT) gene is a direct target of the histone methyltransferase SMYD3. Cancer Res 67: 2626-2631, 2007.

26. Kang X, Chen W, Kim RH, Kang MK and Park NH: Regulation of the hTERT promoter activity by MSH2, the hnRNPs K and D, and GRHL2 in human oral squamous cell carcinoma cells. Oncogene 28: 565-574, 2009.

27. Briatore F, Barrera G, Pizzimenti S, Toaldo C, Casa CD, Laurora S, Pettazzoni P, Dianzani MU and Ferrero D: Increase of telomerase activity and hTERT expression in myelodysplastic syndromes. Cancer Biol and Ther 8: 883-889, 2009.

28. Moriai M, Tsuji N, Kobayashi D, Kuribayashi K and Watanabe N: Down-regulation of hTERT expression plays an important role in 15-deoxy-Delta 12,14-prostaglandin J2-indiced apoptosis in cancer cells. Int J Oncol 34: 1363-1372, 2009. 
29. Noureini SK and Wink M: Transcriptional down regulation of hTERT and senescence induction in HepG2 cells by chelidonine. World J Gastroenterol 15: 3603-3610, 2009.

30. Fu XH, Zhang JS, Zhang $\mathrm{N}$ and Zhang YD: Combination of telomerase antisense oligonucleotides simultaneously targeting hTR and hTERT produces synergism of inhibition of telomerase activity and growth in human colon cancer cell line. World J Gastroenterol 11: 785-790, 2005 .
31. Oken MM, Creech RH, Tormey DC, Horton J, Davis TE, McFadden ET and Carbone PP: Toxicity and response criteria of the Eastern Cooperative Oncology Group. Am J Clin Oncol 5: 649-655, 1982.

32. Astler VB and Coller FA: The prognostic significance of direct extension of carcinoma of the colon and rectum. Ann Surg 139: 846-852, 2003. 